\title{
CERTIFICACIÓN DE CALIDAD PARA EL SISTEMA DE BIBLIOTECAS DE LA FUNDACIÓN UNIVERSITARIA DE CIENCIAS DE LA SALUD
}

Marisol Goyeneche Reina*

\begin{abstract}
"Hay un mundo de diferencia entre el acatamiento y el compromiso. La persona comprometida aporta una energía, una pasión, una excitación que no se puede generar si uno se limita a acatar, aunque este acatamiento sea genuino. La persona comprometida no solo juega; es responsable del juego (...). Un grupo de personas realmente comprometidas (...) representa una fuerza abrumadora. Son capaces de lograr lo que parece imposible" (Peter Senge).
\end{abstract}

Es grato registrar que el sistema de bibliotecas de la Fundación Universitaria de Ciencias de la Salud celebra hoy el inicio de un nuevo ciclo con la certificación entregada por ICONTEC, máximo organismo colombiano para tal fin, que a su vez la avala en el ámbito internacional con el certificado de calidad de IQNET bajo la norma ISO 9001:2008, Sistemas de gestión de la calidad: requisitos, con alcance a la Gestión de Colecciones y Servicios de información del Sistema de Bibliotecas. Este es un gran paso en lo que significa tener y mantener un sistema de gestión de calidad basado en los principios de enfoque al cliente: liderazgo, participación del personal, actividad centrada en procesos, sistema de gestión y mejora continua, que se plasman en hechos y relaciones beneficiosas.

El proceso se inició en septiembre de 2010 cuando el Consejo Superior de la Fundación autorizó mediante Acuerdo No. 300 la contratación de la asesoría de implementación con la firma Instituto Visión Consultoría Empresarial y Económica de la Universidad de la Sabana, y así con el beneplácito de las directivas, el compromiso del equipo de trabajo y el acompaña-

* Bibliotecóloga, Directora del sistema de bibliotecas de la Fundación Universitaria de Ciencias de la Salud. Bogotá DC. Colombia.

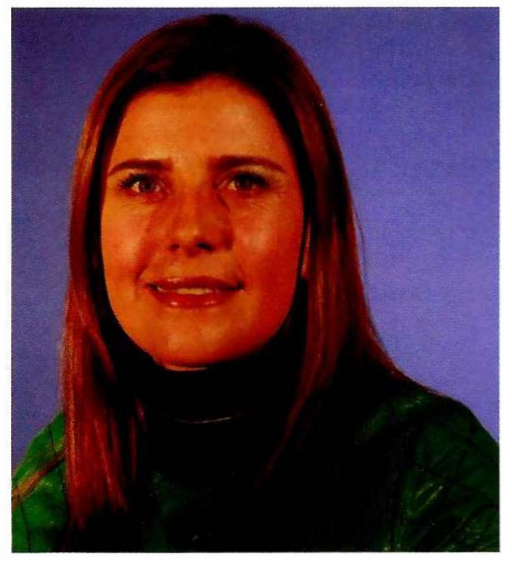

miento de la firma asesora, se asumió el reto a través de la socialización y diagnóstico, la capacitación, la implementación, la evaluación y el seguimiento, para llegar con orgullo a recibir el certificado, el cual sin duda permitirá la mejora interna de los procesos, así como la eficiencia operacional y de los resultados, la reducción de costos, mayor productividad, fiabilidad, seguridad, confianza y por supuesto el incremento en la satisfacción de todos los usuarios.

El sistema de bibliotecas como área pionera dentro de la Fundación logra también el reconocimiento a nivel nacional e internacional como unidad de información que se gestiona a través de resultados, basada en la orientación al cliente, el liderazgo, el desarrollo e implicación de las personas, el aprendizaje, la innovación y la mejora continua, que se traducen en la gestión de sus colecciones bibliográficas y la prestación de servicios de información de calidad que requiera la universidad y la comunidad académica en general. 


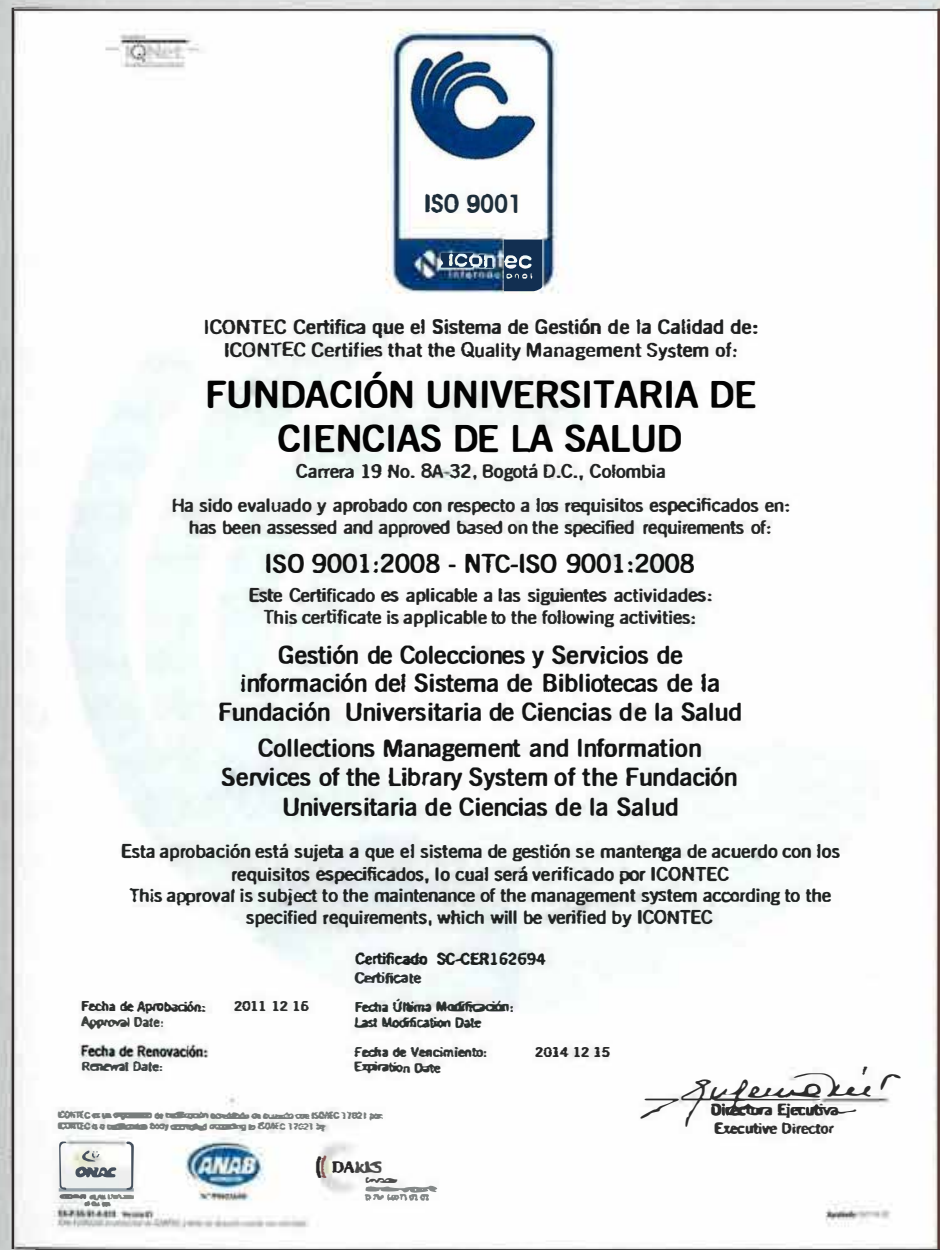

Certifica que el Sistema de Gestión de la Calidad de: ICONTEC Certifies that the Quality Management System of:

\section{CIENCIAS DE LA SALUD}

a el sistema de gestión se mantenga de acuerdo con los , lo cual será verificado por ICONTEC

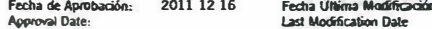

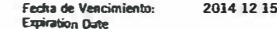

